\title{
Behavior of GFRP-Wood Composite Sandwich Beam-Column Joints with Angle Steels
}

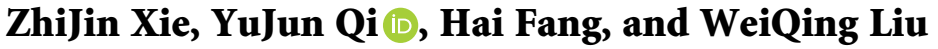 \\ College of Civil Engineering, Nanjing Tech University, Nanjing 211816, China \\ Correspondence should be addressed to YuJun Qi; qiyujun@njtech.edu.cn
}

Received 3 September 2019; Revised 10 May 2020; Accepted 3 June 2020; Published 30 July 2020

Academic Editor: Ayman S. Mosallam

Copyright (c) 2020 ZhiJin Xie et al. This is an open access article distributed under the Creative Commons Attribution License, which permits unrestricted use, distribution, and reproduction in any medium, provided the original work is properly cited.

\begin{abstract}
In this paper, a new type of connection system was proposed for joints between GFRP-wood composite sandwich beams and columns which were made of glass fiber-reinforced polymer (GFRP) face sheets and southern pine wood cores. The connection system comprised steel angles anchored to the column, and the beam was bolted to the angles. Six different connection system configurations were tested to understand the static behavior of the connection system under different parameters including the length of the beam-closed limb and the presence of ribs. The failure modes of the connection system obtained in tests were of three types: yield failure of the angle steels, local crushing failure of the GFRP-wood composite sandwich beam, and tensile failure of the bolt on the beam-closed limb. The initial rotational stiffness values of the three specimens with ribs were $113.75 \%, 119.56 \%$, and $227.94 \%$ higher than the corresponding three specimens without ribs. And the ductility of connection improved by up to $30.28 \%$ due to the presence of stiffener ribs. Based on the tests, the bearing capacity and stiffness of the connection system were predicted. For the specimens without ribs, the method in Eurocode 3 was adopted for bearing capacity and stiffness predictions. For the specimens with ribs, a mechanical model was established for bearing capacity and initial stiffness predictions, which was solved according to the corresponding stress features and failure modes. The analytical results were in good agreement with the experimental results.
\end{abstract}

\section{Introduction}

Glass fiber-reinforced polymer (GFRP) composite sandwich members, which are composed of high-strength GFRP face sheets and a relatively lightweight core, have seen significant growth in structural engineering applications over the last two decades [1-4]. Typical sandwich members with wood cores $[2,5]$ have been used as structural elements in beams [6], floors [7], and roofs [8] because of their excellent bending stiffness and loading capacity and their highstrength weight ratios. For instance, the Foshou Lake Hotel, a three-story GFRP frame structure, was built in Nanjing, China [9], in 2017. In this new structure, a GFRP-wood composite column comprising an inner wood core and outer GFRP face sheets was assembled to resist vertical loads and a damp environment on the lake (Figure 1).

In the past two decades, a number of experimental and analytical studies have been conducted on sandwich members, such as beams $[6,10,11]$, columns $[9,12,13]$, and panels $[14,15]$. For example, Shi et al. [6] investigated the pseudoductile flexural behavior of innovative sandwich beams with an inner wood core and outer GFRP face sheets. Their results indicated that implementing GFRP webs in the sandwich beams improved their flexural performance. Fleck and Sridhar [12] studied the failure modes of sandwich columns with glass fiber-reinforced polymer (GFRP) sheets and PVC foam cores and proposed a simple analytical model to predict the axial strength of these columns, and the predicted results accurately agreed with the experimental values for each failure mode. Zhu et al. [14] studied the bending behavior of an innovative GFRP sandwich panel with GFRP face sheets and a paulownia wood core and found that the bending stiffness and ultimate bending strength of the panel could be enhanced by increasing the web thickness, web height, and face sheet thickness and by reducing the web spacing. The current literature on sandwich core structures 


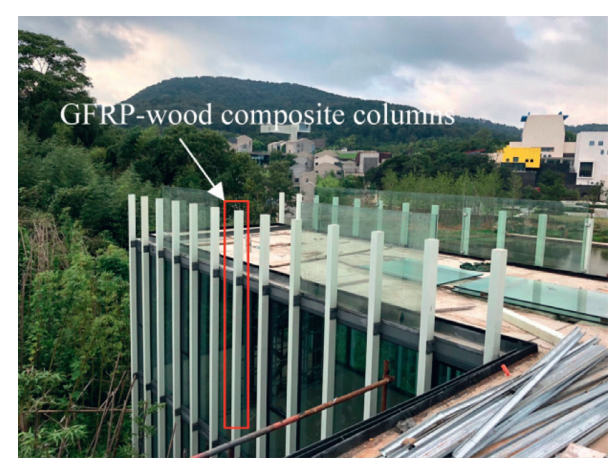

Figure 1: Nanjing Foshou Lake Hotel with GFRP-wood composite columns.

mainly concentrates on members. To utilize members in engineering application, it is necessary to investigate the connection method of members and their connection performance, as the connection method and structural safety depend not only on the structural members but also on the strength and stiffness of their connections and joints [16]. Reliable connections are necessary to transfer the load between the GFRP-wood composite members.

More recently, researchers have focused on the connections of GFRP composite sandwich members in civil engineering construction. For example, Keller et al. [17] proposed a connection system between load-bearing walls and composite sandwich floors with outer GFRP face sheets and an inner foam or balsa wood core. The systems as shown in Figure 2 comprise steel angles anchored to the walls, serving as main supports of the sandwich panels, which are then adhesively bonded or bolted to the angles. They experimentally assessed the connection systems by means of flexural tests on cantilevers. Their results indicated that the usage of the top steel angle increased the rotational stiffness of floor panel-to-wall connections. Compared to bolted connections, adhesively bonded connections typically exhibited lower deformation capacity and higher stiffness but exhibited brittle failure modes. A bolted connection exhibits better plastic deformation capacity than an adhesively bonded connection, which enables bolted connections to avoid brittle failure under rather large deformation conditions. In contrast to adhesively bonded connections, bolted connections increase the structural ductility. Ductility is an important feature for civil engineering design and application. However, the stiffness and bearing capacity of a bolted joint are relatively low. To improve these performance deficiencies, it is necessary to start by improving the angle steel used for bolted connections. The available literature shows that for an angle steel connection, angle steel with ribs can effectively increase the bearing capacity and initial rotational stiffness of the connection. For example, in a steel structure beam and column connection experiment performed by Wang et al. [18], the top and seat angle connection was reinforced with ribs. Through a static loading experiment, they studied the impact of the ribs on the bearing capacity and rotational stiffness of the connection. Their results showed that the initial rotational stiffness and bearing capacity of an SAS-3 top and seat angle with a rib were $98 \%$ and $148 \%$ greater than those of an SA-1 angle without a rib, respectively. Therefore, for the joint of this type of angle, introducing ribs is an effective way to improve the initial rotational stiffness and bearing capacity of the connection.

Because limited information on connecting GFRP-wood composite beams to columns is available in the literature, valuable experiences can be found in published works on pultruded GFRP beam-to-column connections [19-25]. Bank et al. [19] once used pultruded seated angles as web and flange cleats, wherein they connected the pultruded GFRP beam and column with bolts. Their results indicated that these connections led to premature failures, such as webflange separation of the pultruded column and fracture of the pultruded cleat angles, due to the anisotropic nature of pultruded GFRP profiles. To avoid premature failures, Bank et al. [20] used reinforcing elements and go-through bolts were used by to make some improvements, but the modified connections became complicated, making the connections less economical. To prevent the connecting elements from becoming weak links in beam-to-column connections, Mottram and Zheng [21, 22] used steel angles instead of GFRP seated angles to improve the properties of the connections. Their results indicated that the switch to steel angles increased the moment capacity and stiffness by $70 \%$ and $78 \%$, respectively. Moreover, the connection failure shifted from the steel angle connector to the GFRP beams. In addition to common bolt connection, adhesively joined connection in pultrusion profile members is another common research direction. Ascione et al. [23] investigated the axial stiffness of the adhesive connections in composite beams through tests and numerical simulations. The results indicated that the bonded profile represents a valid alternative to the pultruded profile when the latter is not available on the market. GFRP I-beam-column adhesively bonded connections were tested under combined bending and shear in Ascione et al's [24] subsequent research studies. The seat angles at the connection wrapped by a CFRP fabric wrap, and the results indicated that this innovation has changed the failure mode from brittle to pseudoductile. Adhesive connection applied between GFRP hollow column to builtup beam and mechanical behavior under quasistatic, cyclic, fatigue loading was studied by Ascione et al. [25]. The results demonstrate the superior strength and stiffness of the new adhesive connection compared to a similar bolted connection. Therefore, for the connection of a GFRP-wood composite beam, the connection method of existing steel structures can be referenced.

In this paper, a connection system with top and seat angle steels was proposed to improve the bearing capacity and stiffness of the joint between the composite sandwich beam and column. Six pairs of different steel angles were designed and fabricated in this study for the connection of the beam and column members to obtain six different joint specimens. A cantilever loading test was conducted on these six specimens to obtain their typical mechanical behavior and failure modes. The impact of ribs on the failure mode, initial rotational stiffness, yield moment, and ductility of each specimen was analyzed. For specimens without ribs, the 


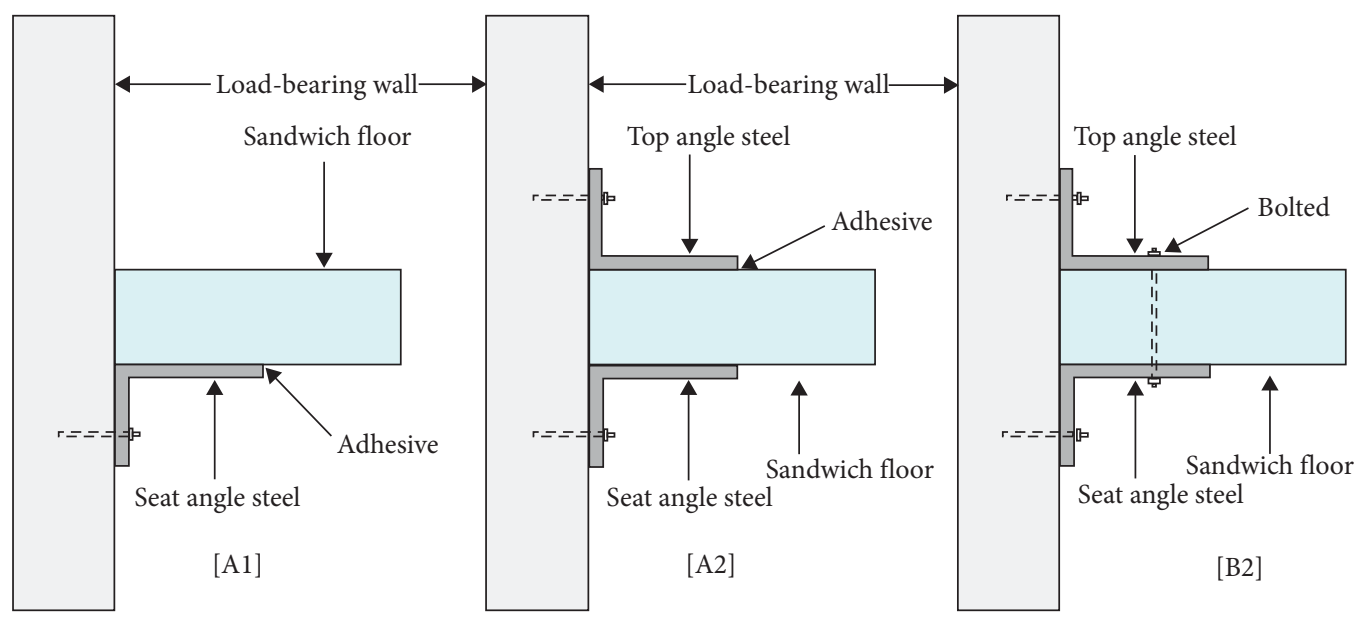

Figure 2: Proposed connection systems (A: adhesively bonded, B: bolted, 1: single bottom steel angle, and 2: top and bottom steel angles).

method in Eurocode 3 [26] was used to predict the bearing capacity and initial rotational stiffness; for specimens with ribs, a mechanical model was established first to predict the bearing capacity and initial stiffness and then solved according to the observed stress features and failure modes. Finally, the predicted results were compared with the experimental results.

\section{Experimental Program}

2.1. Material Properties. The GFRP skins of the composite beam and column tested in this paper consisted of [0/90] symmetric E-glass woven fiber $\left(800 \mathrm{~g} / \mathrm{m}^{2}\right)$. Southern pine with a density of $500 \mathrm{~kg} / \mathrm{m}^{3}$ was used as the core material in this study.

Tensile and compression tests for the GFRP face sheets were performed in accordance with ASTM D3039 [27] and ASTM D3410 [28], respectively. Six cubic southern pine coupons with a $50 \mathrm{~mm}$ thickness were constructed and tested in compression in accordance with ASTM C365 [29]. Table 1 summarizes the properties of the GFRP face sheets and wood cores.

The tensile and yield strength of the angle steel and bolt adopted in this study were obtained in accordance with ASTM E8 [30]. Table 2 summarizes the properties of the angle steel and bolt.

2.2. Top and Seat Angle Steels. Six angle steels of different structures and dimensions were designed for the experiment. The vertical limb bolted to the column is referred to as the column-closed limb, and the horizontal limb bolted to the beam is referred to as the beam-closed limb. The name and dimensions of each part are shown in Figure 3, where $L 1$ represents the distance from the center of the bolt hole to the bottom of the angle steel. All the angle steels and ribs were welded by adopting a Q235 [31] steel plate with a thickness of $8 \mathrm{~mm}$, and the width of the ribs was $100 \mathrm{~mm}$.

2.3. Specimens. A total of 6 joint specimens shown in Figure 4, which were composed of different angle steels (illustrated in Figure 3) and GFRP-wood composite members (illustrated in Figure 5), were tested in this paper. The column-closed limb of the angle steel was connected to the composite column member with four bolts, and the beamclosed limb was connected to the composite beam member with two bolts. Each bolt was $220 \mathrm{~mm}$ in length and $14 \mathrm{~mm}$ in diameter. The details of the specimens are given in Table 3. The serial numbers for the six specimens are TJ-110, TJ-110R, TJ-160, TJ-160-R, TJ-210, and TJ-210-R, where T represents the T-shaped connection, J represents the joint, and $\mathrm{R}$ represents the rib.

The composite sandwich members, which have a rectangular cross section with dimensions of $100 \mathrm{~mm} \times 150 \mathrm{~mm}$, were manufactured at the Advanced Engineering Composites Research Center of Nanjing Tech University, China. The cross section of the southern pine wood core was $90 \mathrm{~mm} \times 140 \mathrm{~mm}$, and the external GFRP sheets were $5 \mathrm{~mm}$ thick, as shown in Figure 5. The lengths of the column and beam members were $1600 \mathrm{~mm}$ and $800 \mathrm{~mm}$, respectively.

2.4. Test Setup and Instrumentation. The static loading tests were performed on a special setup, as shown in Figure 6(a), where the composite sandwich beam was placed horizontally, and the composite sandwich column was placed vertically. Both ends of the column were connected with the foundation through the reaction frame. The loading point was located on the upper part of the beam, $400 \mathrm{~mm}$ from the beam and column interface. Loading was applied by a hydraulic actuator with an axial capacity of $100 \mathrm{kN}$.

Two linear variable displacement transducers (LVDTs) with a stroke of $100 \mathrm{~mm}$ were used to measure the displacement of the beam-closed limb in the seat angle steel and the vertical displacement of the loading point, as shown in Figure 6(b). The rotation of the beam could be determined through these two vertical displacements. For each specimen, the strains in the angle steels were measured with electrical resistance linear strain gauges. The strain gauges were attached to the angle steels and numbered as shown in Figure 6(c). The measured strains were then used to identify the failure mode and compare the effects of limb length and stiffener ribs on the beam-column joint. For the angle steel 
TABLE 1: Mechanical properties of the GFRP and southern pine.

\begin{tabular}{lccc}
\hline Material & Tensile strength $(\mathrm{MPa})$ & Elastic modulus $(\mathrm{GPa})$ & Compressive strength $(\mathrm{MPa})$ \\
\hline GFRP & 291.61 & 21.09 & 168.21 \\
Southern pine & - & 5.87 & 31.88 \\
\hline
\end{tabular}

Table 2: Mechanical properties of the angle steel and bolt.

\begin{tabular}{lccccc}
\hline Material & Yield strength $(\mathrm{MPa})$ & Ultimate tensile strength $(\mathrm{MPa})$ & Ultimate strain & Elastic modulus, $E(\mathrm{MPa})$ & Poisson's ratio, $v$ \\
\hline Q235 & 263 & 444 & 0.146 & 206000 & 0.28 \\
Q235 bolt & 352 & 440 & 0.032 & 206000 & 0.30 \\
\hline
\end{tabular}

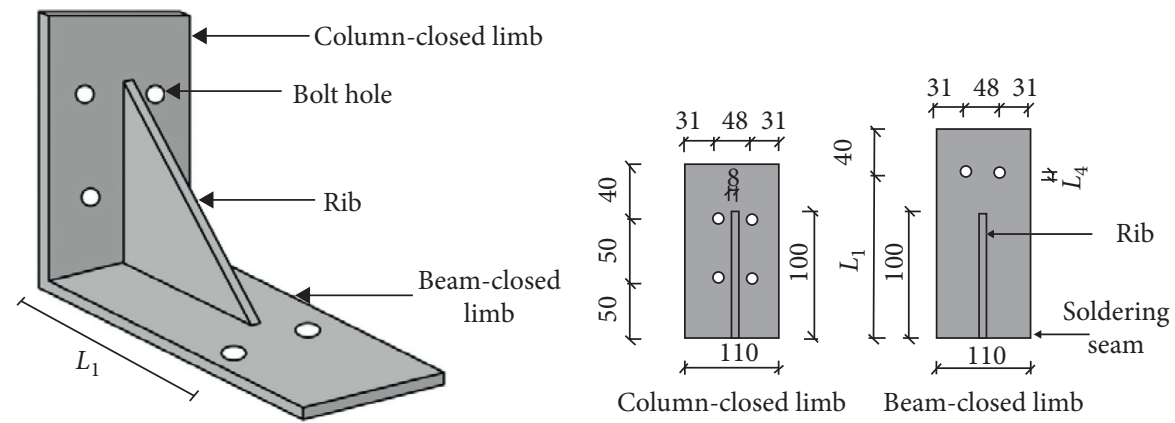

Figure 3: Cross section of the angle steel (units: mm).

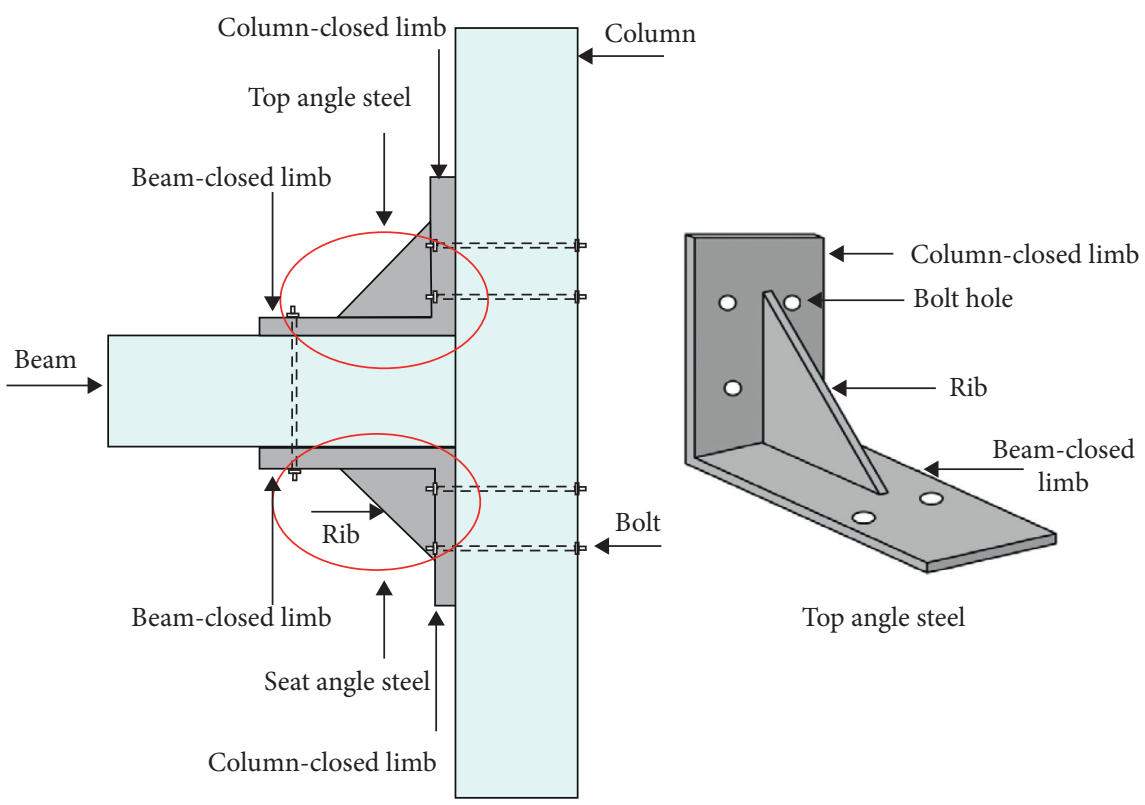

FIGURE 4: Specimens.

specimens with ribs, the length $L_{C}$ of the compression zone was measured where the beam-closed limb in the seat angle steel came into contact with the beam.

The loading was applied in displacement control at a loading rate of $2 \mathrm{~mm} / \mathrm{min}$ for all of the specimens. The tests were stopped when the load of the specimen was reduced by at least $20 \%$ of the maximum load of the specimen.

\section{Experimental Results and Discussion}

Table 4 presents the summary results of all specimens tested in this paper, including the initial rotational stiffness $\left(R_{\mathrm{ki}}\right)$, ultimate bearing capacity $\left(N_{u}\right)$, and failure modes. For further quantification of the mechanical behavior of the specimen, some of the parameters, such as the theoretical 


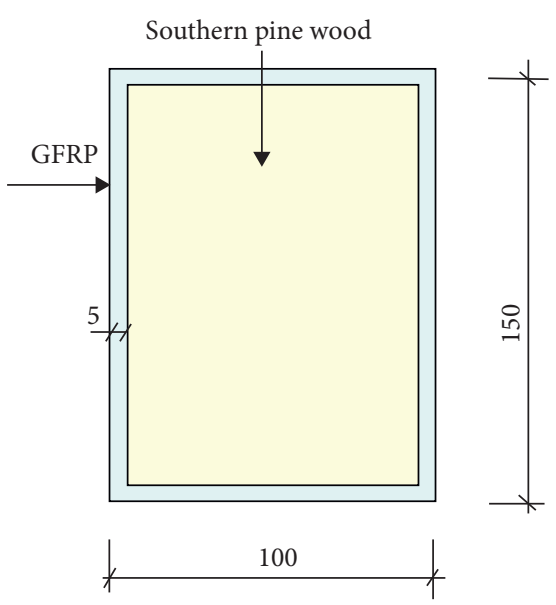

Figure 5: Cross section of the composite sandwich elements (units: $\mathrm{mm})$.

TABLE 3: Dimensions of the angle steel.

\begin{tabular}{lccc}
\hline Specimen & Angle steel & $L 1(\mathrm{~mm})$ & Ribs \\
\hline TJ-110 & 110 & 70 & No \\
TJ-110-R & $110-R$ & 70 & Yes \\
TJ-160 & 160 & 120 & No \\
TJ-160-R & $160-R$ & 120 & Yes \\
TJ-210 & 210 & 170 & No \\
TJ-210-R & $210-R$ & 170 & Yes \\
\hline
\end{tabular}

initial rotational stiffness $\left(R_{\text {pre }}\right)$, theoretical bearing capacity $\left(N_{\text {pre }}\right)$, and yield moment $\left(M_{y}\right)$, are also summarized.

3.1. Failure Modes. The results indicated three different failure modes: yield failure of the angle steel, local crushing failure of the GFRP-wood composite sandwich beam, and tensile failure of the bolt on the beam-closed limb. Detailed descriptions of each type of failure mode are provided in the following sections.

3.1.1. Yield Failure of the Angle Steel. Angle steel yield failure occurred in all specimens without stiffener ribs, including TJ-110, TJ-160, and TJ-210. During the loading process, as a negative bending moment existed at the connection, the upper part of the cross section of the beam end joint was under tension, and the lower part was under compression, resulting in a leftward pulling force, thereby causing the separation of the angle corner from the column. In addition, the separation degree increased as the applied load increased. For the top angle steel, a downward bending deformation began to occur in the beam-closed limb due to the continuous increase in the beam-column rotation. The strain at the corner continued to increase. Take specimen TJ-160 as an example. During the loading process, when the top angle steel was apparently pulled away from the column surface, the strain value at the corner was $1122.81 \times 10^{-6}$, already exceeding the yield strain of the angle, i.e., the angle exhibited a yield failure. The final failure manifested as a total cross section yield (Figure 7). A simplified model for analyzing a bent rod of angle steel with ribs is presented in EC3 [26], in which it is believed that when the steel angle is thinner than the bolt, the plastic hinge will not appear on the bolt. However, the plastic hinge line appears on the bent limb of the angle steel, manifesting as a full cross section yield at the angle steel corner, which is consistent with the experimental results obtained by Wang et al. [18]. Under static loading, yield failure of the angle steel both occurred in specimens SA1 and SAS-2 at the beam-column node of the steel structure adopting angle steel without ribs, and an apparent bending phenomenon occurred in the seat angle steel.

3.1.2. Local Crushing of Beam. Specimens TJ-110-R and TJ$160-\mathrm{R}$ exhibited local crushing failure in the compression zone of the GFRP-wood composite sandwich beam. As with the aforementioned angle steel members without ribs, the beam-closed limb in the top angle steel was subject to a leftward pulling force, causing a tendency for the angle steel corner to separate from the column. However, due to the constraint provided by the stiffener ribs, the bending stiffness of the top angle steel was significantly improved. The bending stiffness was increased due to the presence of the stiffener ribs in the seat angle steel, and the bending point of the beam-closed limb in the seat angle steel was shifted from the corner of the seat angle steel to the rib edge. Two local compression zones appeared on the beam-closed limb in the top and seat angle steel, with the local compression area of the seat angle steel being relatively larger than that in the top angle steel. The local compressive strength of the lower part of the beam increased with increasing load. When the load increased to the local compressive strength of the GFRPwood composite sandwich beam, the beam in the compression zone was crushed. As a result, cracks parallel to the bolt direction appeared on the GFRP face sheet and then continuously developed. Afterwards, the specimen was in a plastic stage. As the loading continued to increase, the specimen finally exhibited a local crushing failure in the compression zone on the lower part of the beam, whereas the wood core of the beam in the compression zone on the upper part of the beam was squeezed out due to continuous longterm loading. Take specimen TJ-160-R as an example. When an apparent crushing phenomenon occurred in the compression zone in the lower part of the beam, the strain at the corner of the column-closed limb in the top angle steel $\left(440 \times 10^{-6}\right)$ was significantly less than that of specimen TJ160. The strain on the rib edge of the beam-closed limb in the seat angle steel was smaller than its yield strain, indicating that the specimen failure was characterized by local crushing of the beam. The failure mode of this specimen was different from the experimental results of Keller et al. [17], in which a balsa core composite sandwich, which was connected to the angle steel via a bolt, exhibited a crack in the balsa core parallel to the bolt under a static loading state. However, they did not observe a local compression zone, as in this study, mainly as the constraint of the stiffener in this experiment increased the rotational stiffness of the connection. Specimens TJ-110-R (Figure 8(a)) and TJ-160-R (Figure 8(b)) both exhibited local crushing failure in the beam 


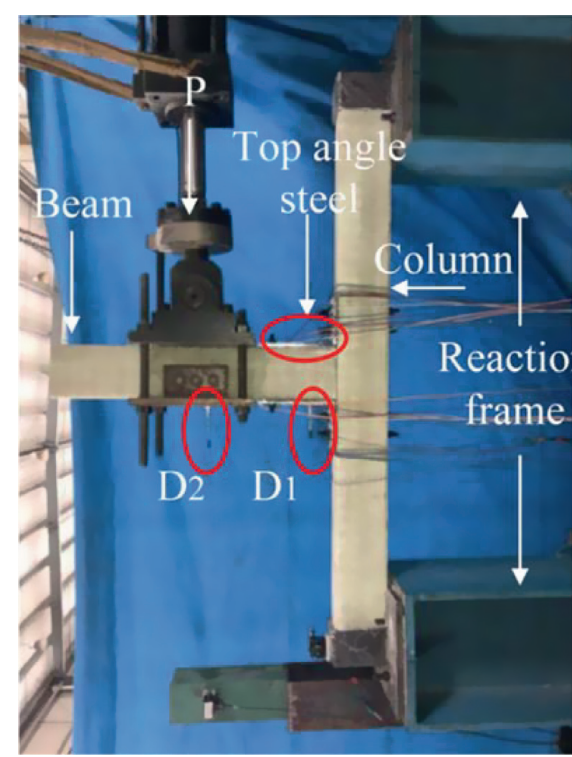

(a)

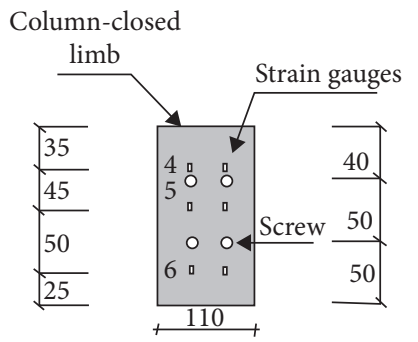

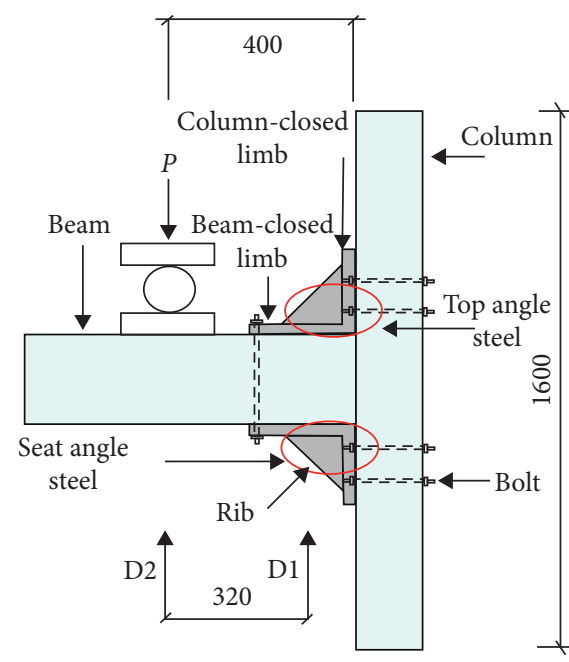

800

(b)

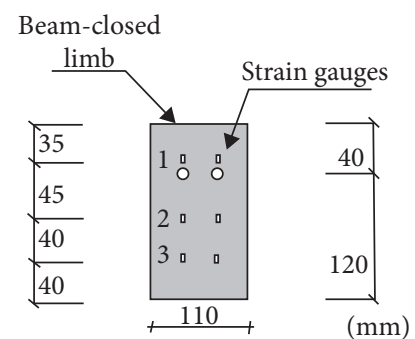

(c)

FIgURE 6: Test setup: (a) photograph and (b, c) schematic diagrams.

TABLE 4: Summary of test results.

\begin{tabular}{lccccccccc}
\hline Specimen. & $N_{u}(\mathrm{kN})$ & $N_{\text {pre }}(\mathrm{kN})$ & $M_{y}(\mathrm{kN} \mathrm{m})$ & $R_{\mathrm{ki}}(\mathrm{kN} \mathrm{m} / \mathrm{rad})$ & $R_{\text {pre }}(\mathrm{kN} \mathrm{m} / \mathrm{rad})$ & $e_{u}(\mathrm{~mm})$ & $e_{y}(\mathrm{~mm})$ & $\mu$ & Failure mode \\
\hline TJ-110 & 25.04 & 26.08 & 6.32 & 80 & 83 & 126.40 & 41.47 & 3.05 & Angle yield \\
TJ-160 & 27.75 & 26.08 & 7.84 & 92 & 83 & 137.12 & 48.29 & 2.84 & Angle yield \\
TJ-210 & 23.46 & 26.08 & 6.01 & 68 & 83 & 98.14 & 38.39 & 2.56 & Angle yield \\
TJ-110-R & 26.69 & 24.28 & 8.24 & 171 & 185 & 101.32 & 27.9 & 3.41 & Local crushing of beam \\
TJ-160-R & 37.67 & 41.88 & 12.88 & 202 & 185 & 97.91 & 26.45 & 3.70 Local crushing of beam \\
TJ-210-R & 45.57 & 43.5 & 13.56 & 223 & 185 & 56.82 & 25.00 & 2.27 & Tensile failure of bolt \\
\hline
\end{tabular}

compression zone. However, as the length of the beamclosed limb of specimen TJ-160-R was relatively longer than that of specimen TJ-110-R, it was responsible for a relatively larger compression zone of its beam compression zone. Under the same local bearing strength, the bearing capacity of TJ-160-R was greater than that of TJ-110-R, which was demonstrated by the fact that cracks appeared later on the GFRP face sheet in TJ-160-R, and the cracks developed only to one-third of the beam height.

3.1.3. Tensile Failure of Bolt. Specimen TJ-210-R exhibited a tensile failure of the bolt. The GFRP-wood composite sandwich beam, subject to the action of an external force $\mathrm{P}$, underwent a downward rotation, leading to a bending deformation in the beam-closed limb of the top and seat angle steel. As the load increased, the bolt transferred the bending deformation of the seat angle steel to the top angle steel via tensile force. A bending along the loading direction began to appear on the rib edge on the beam-closed limb as the top angle steel came under the action of the bolt pulling force. At this time, the increasing load caused an increase in the local bearing area of the GFRP-wood composite sandwich beam on the lower part of seat angle steel. Before the composite beam in the compression zone experienced local crushing failure, the bolt had already reached its ultimate tensile strength. At this moment, the specimen exhibited a brittle failure due to bolt breakage, yet the strain value at the stiffener rib edge of the beamclosed limb in the top and seat angle steel was smaller than 


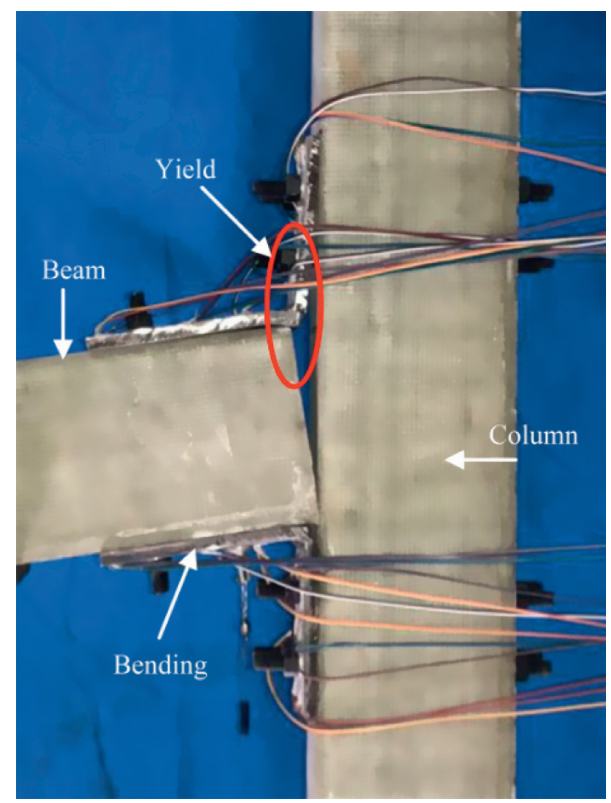

Figure 7: Yield at the corner of the top angle steel (TJ-110).

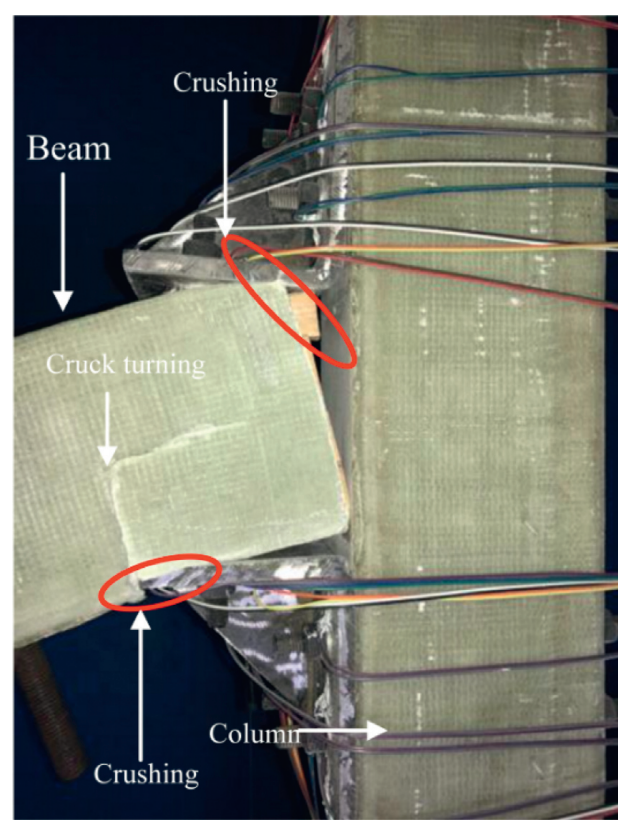

(a)

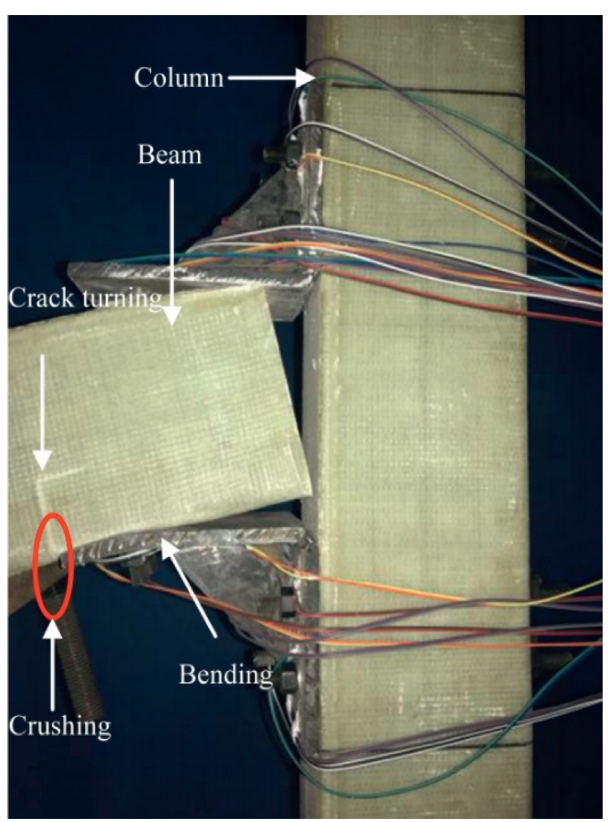

(b)

FIGURE 8: Local crushing failure of the GFRP-wood composite sandwich beam. (a) TJ-110-R. (b) TJ-160-R.

the yield load of the steel, and the failure of the specimen was impacted by the tensile capacity of the bolt, as shown in Figure 9.

3.2. Initial Rotational Stiffness and Bending Moment. The bending moment-rotation response is an important characteristic for evaluating the resistance of a structural system to load. Figure 10 shows the bending moment-rotation curves of the six specimens obtained from the static loading experiment. As shown in Figure 10, the initial bending moment-rotation curve displays a typical elastoplastic characteristic, i.e., the curve exhibits an initial linear development, followed by a yield failure, which is characteristic of a continued decrease in the rigidity of the curve. The member presents an approximately straight line in the later plastic development stage. The bending moment $M$ sustained by the beam end of the specimen and the beam end rotation can be obtained by the following equations, respectively: 


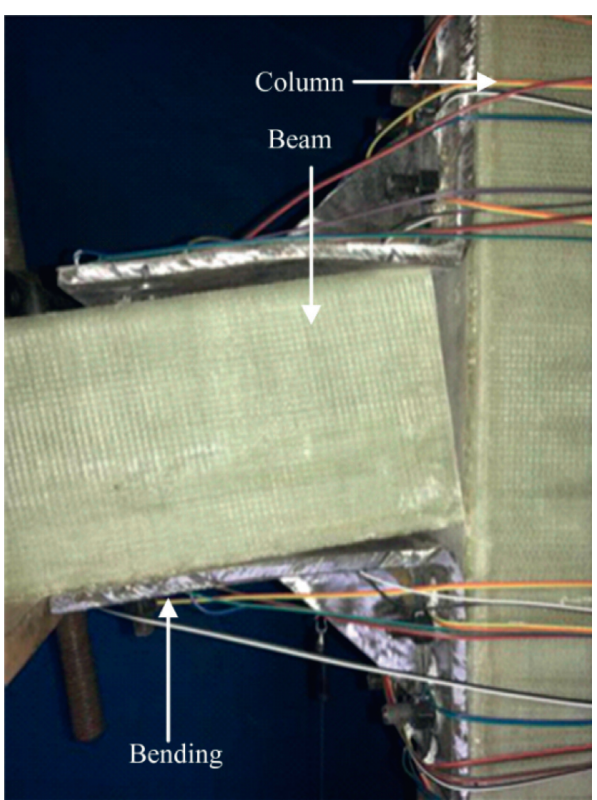

FIgURE 9: Bolt break failure (TJ-210-R).

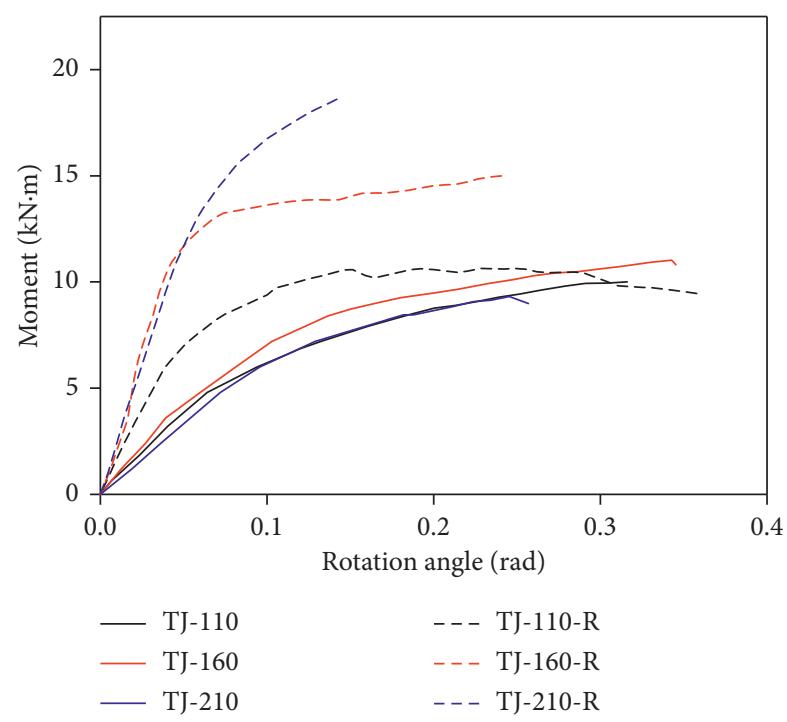

FIgURE 10: Moment-rotation curves.

$$
\begin{array}{r}
M=P \times a_{1}, \\
\theta \approx \tan \theta=\frac{\Delta_{2}-\Delta_{1}}{a_{2}},
\end{array}
$$

where $P$ is the vertical load of the loading point; $a_{1}$ is the distance from the loading point to the beam-column interface; $\Delta 1$ and $\Delta 2$ are the displacement values taken from displacement gauges D1 and D2, respectively; and $a_{2}$ is the distance between displacement gauges D1 and D2.

For the load-displacement curve with no obvious turning points, a specific method is required to determine the corresponding yield point position. In fact, in previous research, there has been no uniform evaluation method for determining the yield point in a curve that shows no obvious turning point [32]. Feng et al. [33] reviewed the existing literature, and the methods mainly include the graphing method shown in Figure 11(a), the equal energy method shown in Figure 11(b), and the residual plastic deformation method shown in Figure 11(c). However, the available definition of the yield point is insufficient both physically and practically, and a more explicit definition method needs to be provided. In this paper, the yielding point on the bending moment-rotation curve was determined according to the method of Feng et al. [34], who believed that the slope of the tangent to the yielding point is the same as the slope of the line connecting the peak point and the origin, as shown in Figure 11(d); herein, this method is considered feasible for the traditional elastoplastic curve. The experimental results using this method are shown in Table 4.

As seen from the results in Table 4, the yield load of the specimens with stiffener ribs is much higher than that of the specimens without stiffener ribs. For example, the yield loads of TJ-110-R, TJ-160-R, and TJ-210-R are $41.58 \%, 64.29 \%$, and $125.62 \%$ higher than those of TJ-110, TJ-160, and TJ210, respectively, because the presence of stiffener ribs changes the failure mode of the specimen. The macroscopic nonlinear yield of the specimen without stiffener ribs is attributed to the yield of the angle steel. The macroscopic nonlinear yield of the specimen with stiffener ribs is caused by local crushing of the sandwich beam or bolt breakage. The bearing capacity of the former is obviously smaller than that of the latter. Therefore, the yield bearing capacity of the specimen with stiffener ribs is obviously higher than that of the specimen without stiffener ribs.

The tangent slope $R_{k i}$ of the initial connection is taken as the initial rotational stiffness of the connection. The experimental results are shown in Table 4 . The initial rotational stiffnesses of TJ-110-R, TJ-160-R, and TJ-210-R are $113.75 \%, 119.56 \%$, and $227.94 \%$ greater than those of TJ$110, \mathrm{TJ}-160$, and TJ-210, respectively, indicating that the presence of stiffener ribs has a significant constraint on the rotation of the connection and effectively improved the initial stiffness of the connection. In addition, for a certain length of the stiffener rib, a longer limb means a larger initial rotational stiffness. However, for angle steel without ribs, different limb lengths have little impact on the initial rotational stiffness.

3.3. Ductility. Ductility is an important characteristic of evaluating structural deformability. This study used the method of ductility calculation that was defined in [35]; namely, the maximum displacement was divided by the yield point displacement:

$$
\mu=\frac{e_{u}}{e_{y}}
$$

where $\mu$ is the ductility ratio, $e_{u}$ corresponds to the maximum displacement, and $e_{y}$ represents the yielding displacement.

The maximum displacement $e_{u}$ of the specimen is based on the displacement corresponding to the peak load. The 


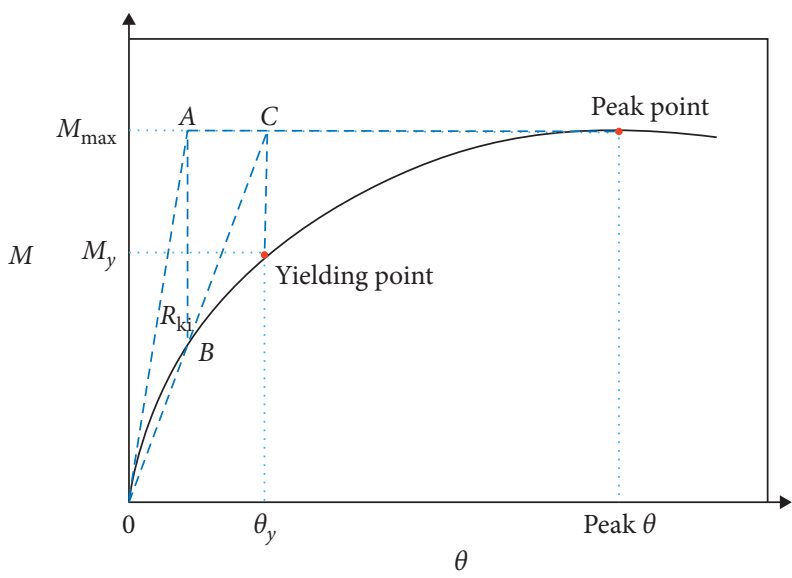

(a)

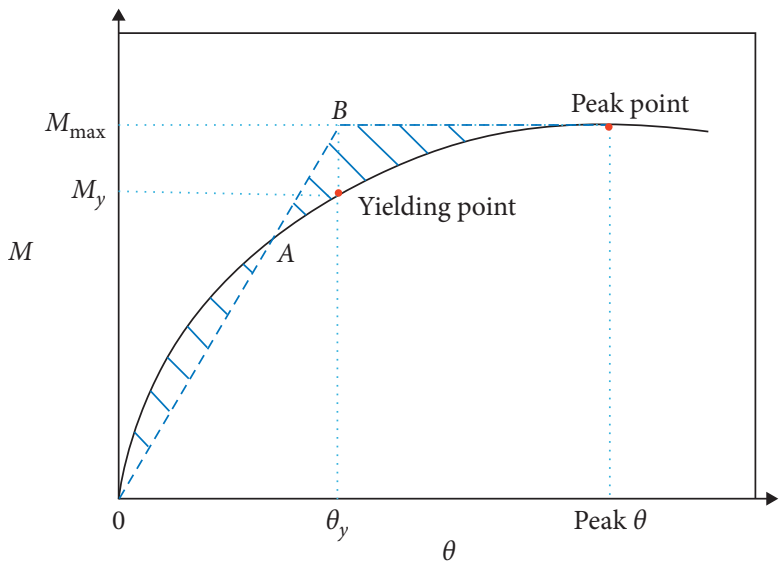

(c)

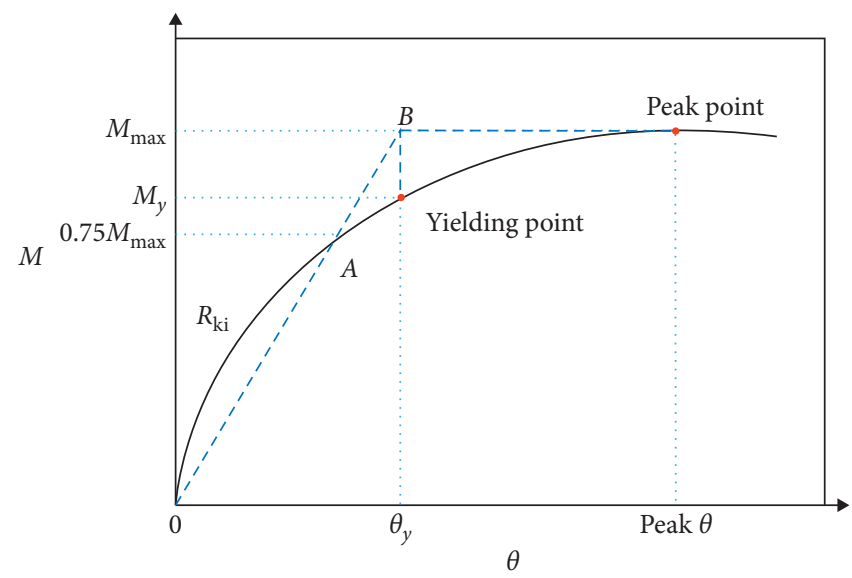

(b)

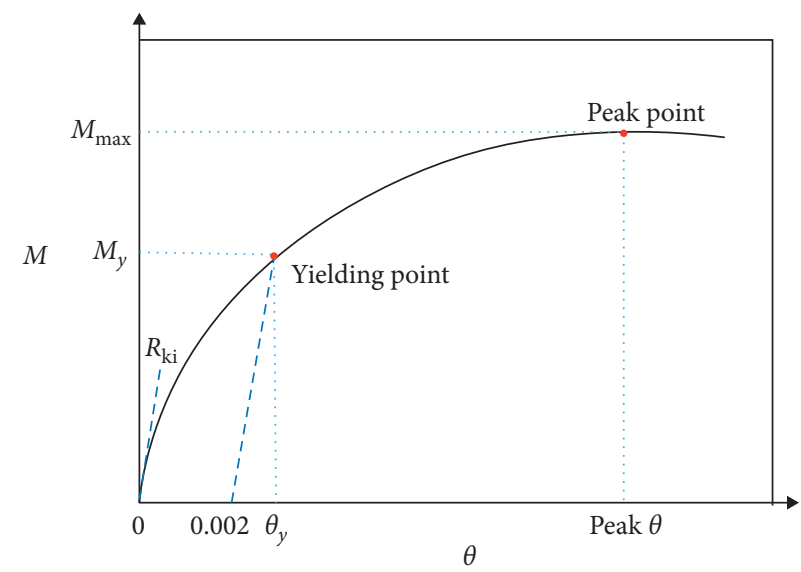

(d)

Figure 11: Key parameter definition of joints.

ductility coefficient of each specimen is derived from (3) and is listed in Table 4.

The introduction of ribs to the angle steel specimens can significantly improve the ductility of the specimen. For example, the ductility of TJ-110-R was $11.8 \%$ greater than that of TJ-110, and the ductility of TJ-160-R was $30.28 \%$ greater than that of TJ-160. However, when the beam-closed limb was too long and the area of the compression zone increased, the breakage failure of the bolt shifted to brittle failure.

\section{Theoretical Analysis}

4.1. Analysis of Bearing Capacity. According to the failure mode obtained in the experiment, the bearing capacity can be calculated as follows:

(1) The breakage failure bearing capacity $P 1$ of the bolt: this bearing capacity has nothing to do with the stiffener ribs; this bearing capacity depends solely on the performance of the bolt itself. When the area of the local compression zone is excessively large and the crushing failure bearing capacity exceeds the ultimate tensile strength of the bolt, the failure mode is manifested as brittle failure

(2) The yield failure bearing capacity $P 2$ of angle steel: for specimens without stiffener ribs, the beam-closed limb in the top angle steel is subject to a leftward pulling force, causing a yield failure at the corner of the top angle steel

(3) Local crushing failure bearing capacity P3: exclusively for specimens with stiffener ribs, the local compressive load of the beam in the compression zone is excessively large, resulting in a local crushing failure of the beam.

4.1.1. Breakage Failure Bearing Capacity P1 of the Bolt. When the compression area of the GFRP-wood composite sandwich beam at the joint is large, the GFRP-wood composite sandwich beam does not exhibit local collapse. The bearing capacity of the connection at this moment depends on the tensile capacity of the bolt. The maximum 
pulling force of the single bolt is determined by the following [36]:

$$
\begin{aligned}
& B_{n}=f_{y}^{b} \frac{\pi d_{e}^{2}}{4}, \\
& F_{b}=n_{b} B_{n},
\end{aligned}
$$

where $n_{b}$ is the number of bolts at the joint of the angle steel under tension and the column flange, $B_{n}$ is the ultimate bearing capacity of a single bolt, $f_{y}^{b}$ is the design value for the tensile strength of the bolt, and $d_{e}$ is the effective diameter of the bolt.

4.1.2. Yield Failure Bearing Capacity P2 of the Angle Steel. For the angle steel specimens with ribs, when the angle steel is thinner than the bolt, the plastic hinge will not appear on the bolt. However, the plastic hinge line appears on the bent limb in the angle steel. A calculation method for a simplified bent rod considering the impact of the bolt diameter is proposed in EC3 [26]. According to this method, a full cross section yield appears on the angle steel in the bolt center. The subscripts $t$ and $s$ in relation to calculation represent the top angle steel and seat angle steel, respectively:

$$
\begin{aligned}
T_{T 1} & =\frac{M_{p l . R d}\left(4 n_{1}-e_{w}\right)}{\left[2 m_{1} n_{1}-e_{w}\left(m_{1}+n_{1}\right)\right]}, \\
Q & =\frac{T m_{1}}{\left(2 n_{1}\right)}, \\
M_{p l . R d} & =\frac{b_{a} t_{t}^{2} f_{y}}{4}, \\
e_{w} & =\frac{d_{w}}{4},
\end{aligned}
$$

where $d_{w}$ is the net diameter and $m$ is the effective bending height of the angle steel.

The calculation formulas for effective bolt spacing in EC3 2005 [26] are as follows (for a schematic diagram, see Figure 12):

$$
\begin{array}{ll}
m_{1.1}=m-0.8 r_{a}, & \left(g \leq 0.4 t_{t}\right), \\
m_{1.2}=m+0.5 t_{t}, & \left(g>0.4 t_{t}\right) .
\end{array}
$$

4.1.3. Local Crushing Failure Bearing Capacity P3. Figure 13 is a simplified calculation diagram of the bearing capacity proposed in this paper. When the angle steel specimens with ribs were finally damaged, the bolt came under tension, and local compressive damage zones appeared in the upper and lower parts of the beam, which were located in the upper part of the beam-closed limb in the top angle steel and the lower part of the beam-closed limb in the seat angle steel, respectively. According to the experimental phenomenon and failure mode, the GFRP-wood composite sandwich beam is used as an isolated body to establish a mechanical model for

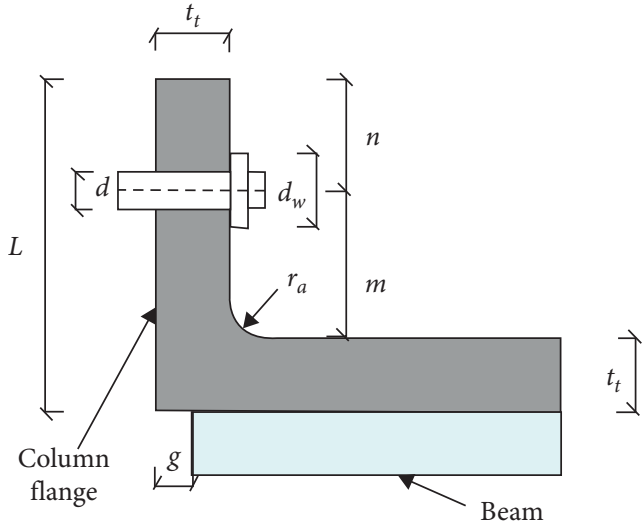

FIGURE 12: Calculation of effective bolt spacing (units: $\mathrm{mm}$ ).

mechanical analysis. The following basic assumptions are adopted for this analysis:

(1) When the distance between the external force $P$ and the bottom surface of the beam end is definite $\left(L_{P}=400 \mathrm{~mm}\right)$, the torque reduction caused by the beam-column rotation is not considered, and the force always acts perpendicularly on the upper surface of the beam.

(2) When the tensioned bolt is broken, the pulling force is perpendicular to the length direction of the beam.

(3) When the local compression area where the upper part of the beam comes into contact with the beamclosed limb in the top angle steel is small, the influence of the resultant force of this part is not disregarded, and the application point is simplified as $\mathrm{A}$.

(4) The rotation angle of the beam is small. Therefore, the reduction in torque caused by the rotation is disregarded. The distance $L_{S}$ from the application point of the resultant force to the bottom end of the beam is taken as the torque of the resultant force.

The torque balance equation is given as follows:

$$
\int_{y_{3}}^{y_{4}} q b y L_{s} \mathrm{~d} y=P L_{P},
$$

where $L_{P}$ is the torque from the external force $P$ to point A, $L_{S}$ is the torque from the resultant force point on the compressive side of the seat angle steel to point $\mathrm{A}, d_{1}$ is the height $(100 \mathrm{~mm})$ of the GFRP-wood composite sandwich beam, and $q$ is the normal pressure between the GFRP-wood composite sandwich beam and the angle steel.

For the computation, it is only necessary to know the magnitude of the resultant compressive stress force and the position of the application point of the GFRP-wood composite sandwich beam in the compression zone. The equivalent rectangular stress diagram is used in place of the theoretical stress diagram for further simplification. The principle of equivalence is the equivalence of the resultant pressure in the compression zone of the GFRP-wood 


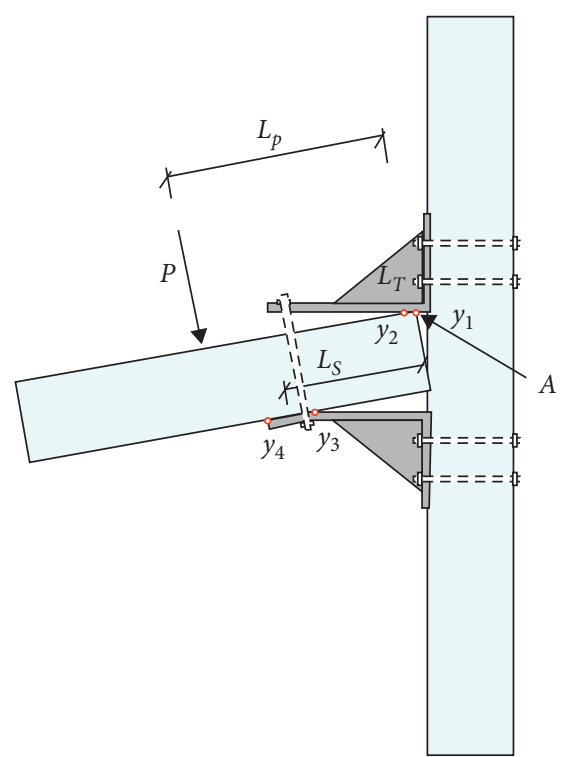

(a)

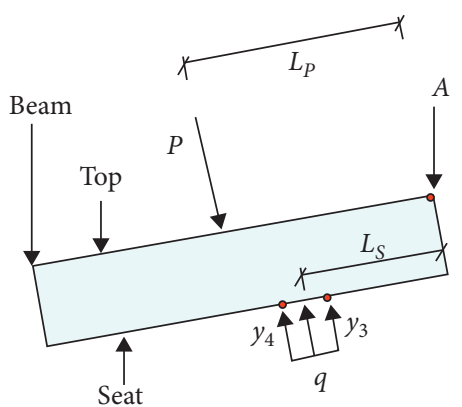

(b)

FIgURE 13: Calculation diagram of bearing capacity.

composite sandwich beam and the equivalence of the bending moment of the section; hence, after equivalence, the magnitude of the resultant force of the GFRP-wood composite sandwich beam in the compression zone is the same, and the application position of the resultant force remains unchanged:

$$
q={ }_{\beta} q_{0},
$$

where $\beta$ is the load unevenness coefficient, which is related to the distribution of compressive stress on the contact surface of the GFRP-wood composite sandwich beam.

In Figure 14, $y_{4}$ and $y_{3}$ are the upper and lower bounds of the compression zone of the GFRP-wood composite sandwich beam on the seat angle steel, respectively, and $L_{c}$ is the actual measured compression zone length in the experiment of the stiffened angle steel specimen. The $L_{c}$ values of TJ-110-R, TJ-160-R, and TJ-210-R are $36.0 \mathrm{~mm}, 41.2 \mathrm{~mm}$, and $46.1 \mathrm{~mm}$, respectively.

The torque $L_{s}$ from the application point of the resultant force in the compressive zone of the beam lower side to point A can be expressed as shown in the following equation:

$$
L_{s}=\frac{L_{1}+L_{2}-L_{C}}{2} \text {, }
$$

where $L_{1}$ is the distance from the bottom of the angle steel to the centerline of the bolt hole on the beam-closed limb, $L_{2}$ is the length from the centerline of the bolt on the beam-closed limb to the free edge ( $40 \mathrm{~mm}$ in this study) (illustrated in Figure 15) and $L_{c}$ is the measured length of the compressive zone on the beam-closed limb in top and seat angle steel.

\subsubsection{Comparison of the Calculated Results and Experimental} Values. Table 5 summarizes the predicted bearing capacity of the specimens under static loading. The proposed formula estimates the loading capacity of the specimens with a standard deviation of 0.11 . The maximum deviations
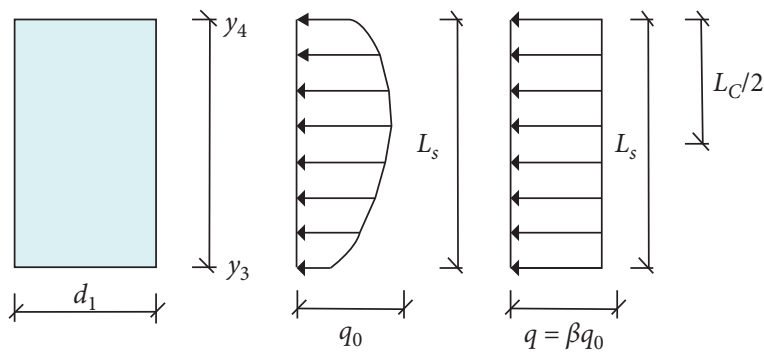

FIgURE 14: Calculation diagram of the stiffened angle steel.

between the experimental value and the calculated value are $2.62 \mathrm{kN}$ and $4.21 \mathrm{kN}$, appearing in TJ-210 and TJ-160-R, respectively.

\subsection{Elastic Stiffness of the Connection}

4.2.1. Initial Rotational Stiffness of the Connection for Angle Steel without Stiffener Ribs. When the top and seat angle steel joint is damaged, the connection rotates around a rotational center $\mathrm{C}$ of the seat angle steel, whereas the top angle steel provides resistance for the moment and shearing force of the beam end. The paper adopts the following calculation assumptions:

(1) The connected rotational center is located at point $\mathrm{C}$ at the junction of the GFRP-wood composite sandwich beam end and the beam-closed limb of the seat angle steel

(2) The top angle steel can be considered a cantilever whose fixed end is assumed to be located on the edge of the bolt hole of the column-closed limb in the top angle steel 


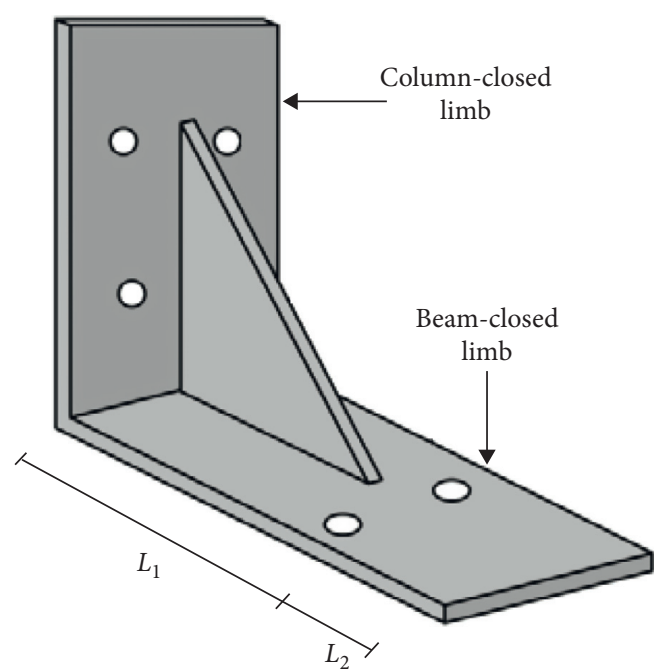

(Top angle steel)

FIGURE 15: $L_{1}$ and $L_{2}$.

TABLE 5: Comparison of the predicted and experimental bearing capacity.

\begin{tabular}{lccc}
\hline Specimen & $N_{\mathrm{u}}(\mathrm{kN})$ & $N_{\text {pre }}(\mathrm{kN})$ & $N_{\text {pre }} / N_{\mathrm{u}}$ \\
\hline TJ-110 & 25.04 & 26.08 & 1.04 \\
TJ-160 & 27.75 & 26.08 & 0.94 \\
TJ-210 & 23.46 & 26.08 & 1.11 \\
TJ-110-R & 26.69 & 24.28 & 0.91 \\
TJ-160-R & 37.67 & 41.88 & 1.11 \\
TJ-210-R & 45.57 & 43.5 & 0.95 \\
\hline
\end{tabular}

(3) In contrast to the top angle steel, the resistance moment of the seat angle steel at point $C$ is very small and can be overlooked

Based on the above assumptions and considering the impact of shear deformation, the derivation process is as follows. First, the main parameters of the top and seat angle steel in the derivation process are introduced as follows (illustrated in Figure 16): $t$ is the thickness of the angle steel, $g_{1}$ is the distance from the centerline of the beam-closed limb in top angle steel to the closest nut edge on the column-closed limb, $d_{w}$ is the nut diameter, $d_{1}$ is the height of the GFRPwood composite sandwich beam section, and subscripts $t$ and $s$ represent the top angle steel and seat angle steel, respectively.

The shear deformation coefficient $K$ is set to $6 / 5$, and the vertical displacement of the top angle steel caused by the surface force Ft of the GFRP-wood composite sandwich beam can be expressed as follows:

$$
\begin{aligned}
\Delta_{t} & =\Delta_{1}+\Delta_{2}=\int_{0}^{g_{1}} \frac{(-x)\left(-F_{t} x\right)}{E I_{t}} \mathrm{~d} x+\kappa \int_{0}^{g_{1}} \frac{(-1)\left(-F_{t}\right)}{G A} \mathrm{~d} x \\
& =\frac{F_{t} g_{1}^{3}}{3 E I_{t}}+\frac{6}{5} \frac{F_{t} g_{1}}{G A},
\end{aligned}
$$

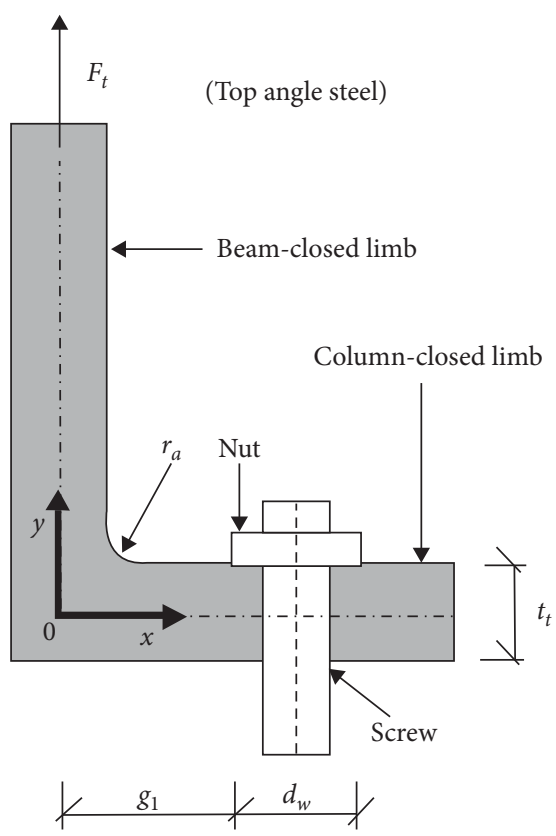

Figure 16: Computational schematic diagram (units: mm).

where the Poisson ratio is $\mu=0.3(E / G)=2(1+\mu)=2.6$ and $\left(I_{t} / A\right)=\left(t_{t}^{2} / 12\right) \mathrm{A}=12 I_{t} / t_{t}^{2}$. Hence, the vertical displacement of the top angle steel can be derived as follows:

$$
\Delta_{t}=\frac{F_{t} g_{1}^{3}}{3 E I_{t}}+\left(\frac{6}{5} \times \frac{1.3}{2}\right) \frac{F_{t} g_{1} t_{t}^{2}}{3 E I_{t}}=\frac{F_{t} g_{1}\left(g_{1}^{2}+0.78 t_{t}^{2}\right)}{3 E I_{t}} .
$$

Additionally, because $\Delta_{t}=d_{1} \times \theta_{t}$ and $M=d_{1} \times F_{t}$, the initial connection stiffness $R_{\mathrm{ki}}$ of the upper and lower flange of the angle steel can be derived as follows:

$$
R_{k i}=\frac{M}{\theta_{r}}=\frac{3 E I d_{1}^{2}}{g_{1}\left(g_{1}^{2}+0.78 t_{t}^{2}\right)} .
$$

4.2.2. Initial Rotational Stiffness of the Stiffened Angle Steel Node. The basic assumptions for calculation of the angle steel specimens with ribs are still the same as those for the angle steel specimens without ribs. However, given the presence of stiffener ribs, the inertia moment of the section is constantly changing. In the equation, $L_{3}$ is the width of the stiffener rib (the width and height of the stiffener rib in this paper are both $100 \mathrm{~mm}$ ), $t$ is the thickness of the stiffener rib (which is $80 \mathrm{~mm}$ in this paper), $g_{2}$ is the distance between the right-side surface of the beam-closed limb and the edge of the closest nut connected to the GFRP-wood composite sandwich beamcolumn joint, $d_{w}$ is the nut diameter, $d_{1}$ is the section height of GFRP-wood composite sandwich beam, and subscripts $t$ and $s$ represent the top angle steel and seat angle steel, respectively. The 1-1 section is taken for calculation as shown in Figure 17(a). The schematic diagram for the calculation is shown in Figure 17(b) for integral computation.

The deformation coefficient $K$ is set to $6 / 5$, and the vertical displacement of the top angle steel caused by the 


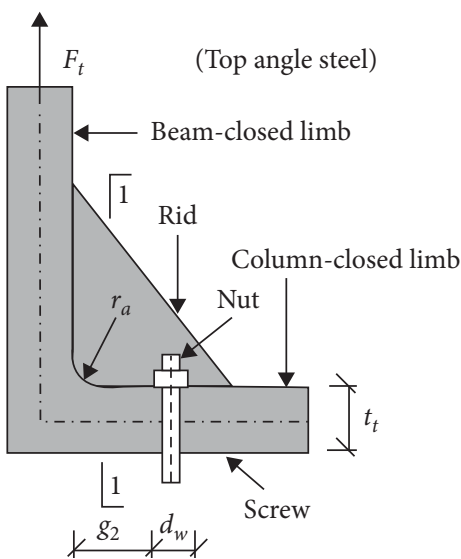

(a)

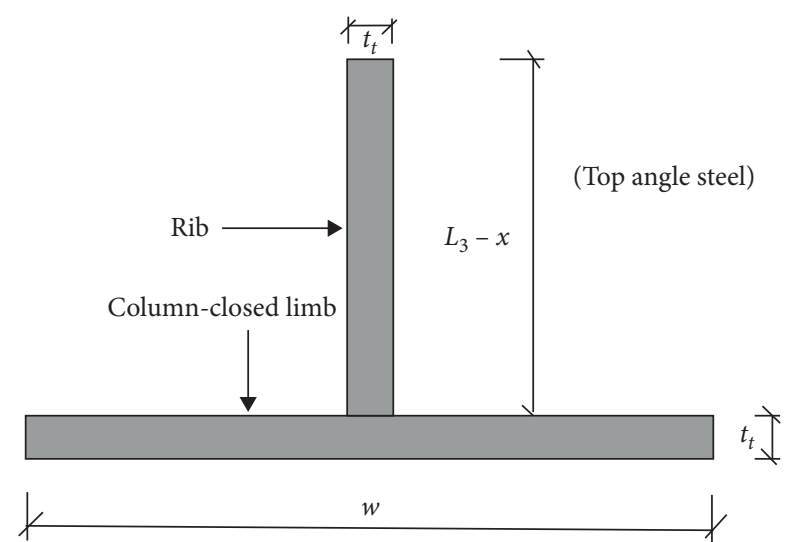

(b)

FIGURE 17: Schematic diagram for calculation of the initial stiffness of stiffened angle steel (units: mm).

surface force $F_{t}$ of the GFRP-wood composite sandwich beam can be expressed as follows:

$$
\Delta_{t}=\Delta_{1}+\Delta_{2}=\int_{0}^{g_{2}} \frac{(-x)\left(-F_{t} x\right)}{E I\left(x_{t}\right)} \mathrm{d} x+\kappa \int_{0}^{g_{2}} \frac{(-1)\left(-F_{t}\right)}{G A(x)} \mathrm{d} x .
$$

Due to the presence of the stiffened angle steel, the shear deformation is small. Therefore, the impact of shear deformation is disregarded. Then, the equation can be simplified as follows:

$$
\Delta_{t}=\int_{0}^{g_{2}} \frac{(-x)\left(-F_{t} x\right)}{E I\left(x_{t}\right)} \mathrm{d} x,
$$

where the inertia moment is a function of $x$, which can be expressed as follows:

$$
\begin{aligned}
{\left[w t_{t}+t_{t}\left(L_{3}-x\right)\right] y_{0}=} & w t_{t} \frac{t_{t}}{2}+\left(L_{3}-x\right) t_{t}\left(t_{t}+\frac{L_{3}-x}{2}\right), \\
I_{(X)_{t}}= & \frac{w t_{t}^{3}}{12}+w t_{t}\left(y_{0}-\frac{t_{t}}{2}\right)^{2}+\frac{t_{t}\left(L_{3}-x\right)^{3}}{12} \\
& +t\left(L_{3}-x\right) t\left(t_{t}+\frac{L_{3}-x}{2}-y_{0}\right)^{2} .
\end{aligned}
$$

Equations (15)-(17) are combined to obtain $\Delta_{1}$.

In addition, since $\Delta_{t}=d_{1} \times \theta_{t}$ and $M=d_{1} \times F_{t}$, the initial connection stiffness $R_{k i}$ of the upper and lower flange of angle steel is expressed as follows:

$$
R_{k i}=\frac{M}{\theta_{r}} .
$$

4.2.3. Comparison of the Theoretical Values and Experimental Values. Table 6 summarizes the predicted initial rotational stiffness of the specimens under static loading.
TABLE 6: Comparison of the predicted and experimental initial rotational stiffness values.

\begin{tabular}{lccc}
\hline Specimen & $R_{\mathrm{ki}}(\mathrm{kN} \mathrm{m} / \mathrm{rad})$ & $R_{\text {pre }}(\mathrm{kN} \mathrm{m} / \mathrm{rad})$ & $R_{\text {pre }} / R_{\mathrm{ki}}$ \\
\hline TJ-110 & 80 & 83 & 1.04 \\
TJ-160 & 92 & 83 & 0.90 \\
TJ-210 & 68 & 83 & 1.22 \\
TJ-110-R & 171 & 185 & 1.08 \\
TJ-160-R & 202 & 185 & 0.92 \\
TJ-210-R & 223 & 185 & 0.83 \\
\hline
\end{tabular}

The proposed formula estimates the initial rotational stiffness of the specimens with a standard deviation of 0.13 . The maximum deviation between the experimental value and theoretical value is $22 \%$, which appears in TJ210.

\section{Conclusions}

In this paper, a new type of connection system was proposed for joints between GFRP-wood composite sandwich beams and columns. This paper investigated failure modes and mechanical characteristics including bearing capacity, stiffness of the connection, and ductility. A mechanical model was established for bearing capacity and initial stiffness predictions. The corresponding major conclusions are summarized as follows:

(1) The beam-column joint specimens adopting top and seat angle steel for connection mainly exhibited three typical failure modes under static loading: yield failure of the angle steel, local crushing failure of the wood-FRP composite beam, and breakage failure of the bolt on the beam-closed limb

(2) Compared with the top and seat angle steel specimens without ribs, the top and seat angle steels with ribs exhibit a $227.94 \%$ higher initial rotational stiffness and a $125.62 \%$ higher yield load

(3) When the length of the beam-closed limb is in a proper range, the presence of stiffener ribs in the top 
and seat angle steel can improve the ductility of the connection by up to $30.28 \%$. However, beyond a certain range, the ductility of the connection will not be improved. At this moment, the bearing capacity of the specimen connection is determined by the tensile capacity of the bolt, which manifests as a brittle failure

(4) In this paper, a method is proposed to predict the initial stiffness and bearing capacity for this type of beam-column joint. For the connection of angle steel specimens without ribs, the simplified calculation model for a bent rod from EC3 has a good predictive power. For an angle specimen with a rib, mechanical models for calculating the bearing capacity and initial stiffness are proposed, and the theoretical equations for the solution are also established. The calculation results are in good agreement with the experimental results, indicating that the method proposed in this paper can accurately predict the bearing capacity and initial rotational stiffness of stiffened top and seat angle steel specimens.

\section{Data Availability}

The data used to support the findings of this study are available from the corresponding author upon request.

\section{Conflicts of Interest}

The authors declare that they have no conflicts of interest regarding the publication of this paper.

\section{Acknowledgments}

This research was funded by the National Natural Science Foundation of China (Grant no. 51778286) and the National Natural Science Foundation of Jiangsu Province (Grant no. BK20171469).

\section{References}

[1] A. Manalo, T. Aravinthan, A. Fam, and B. Benmokrane, "State-of-the-art review on FRP sandwich systems for lightweight civil infrastructure," Journal of Composites for Construction, vol. 21, no. 1, p. 04016068, 2017.

[2] M. Osei-Antwi, J. de Castro, A. P. Vassilopoulos, and T. Keller, "FRP-Balsa composite sandwich bridge deck with complex core assembly," Journal of Composites for Construction, vol. 17, no. 6, p. 04013011, 2013.

[3] L.-Z. Li, X. Liu, J.-T. Yu et al., "Experimental study on seismic performance of post-fire reinforced concrete frames," Engineering Structures, vol. 179, pp. 161-173, 2019.

[4] L. Wang, Z. M. Wu, W. Q. Liu, and L. Wan, "Structural behavior of load-bearing sandwich wall panels with GFRP skins and a foam-web core," Science and Engineering of Composite Materials, vol. 25, no. 1, pp. 173-188, 2016.

[5] Q. Yujun, X. Wei, L. Weiqing et al., "Experimental study of the flexural and compression performance of an innovative pultruded glass-fiber-reinforced polymer-wood composite profile," PLoS One, vol. 10, no. 10, Article ID e0140893, 2015.
[6] H. Shi, W. Liu, H. Fang, Y. Bai, and D. Hui, "Flexural responses and pseudo-ductile performance of lattice-web reinforced GFRP-wood sandwich beams," Composites Part B: Engineering, vol. 108, pp. 364-376, 2017.

[7] Q. Yujun, F. Hai, L. Weiqing et al., "Experimental study of the bending properties and deformation analysis of web-reinforced composite sandwich floor slabs with four simply supported edges," PLoS One, vol. 11, no. 2, Article ID e0149103, 2016.

[8] T. Keller, C. Haas, and T. Vallée, "Structural concept, design, and experimental verification of a glass fiber-reinforced polymer sandwich roof structure," Journal of Composites for Construction, vol. 12, no. 4, pp. 454-468, 2008.

[9] Y. Qi, L. Xie, Y. Bai, W. Liu, and H. Fang, "Axial compression behaviours of pultruded GFRP-wood composite columns," Sensors, vol. 19, no. 4, p. 755, 2019.

[10] Y. Qi, H. Fang, H. Shi, W. Liu, Y. Qi, and Y. Bai, "Bending performance of GFRP-wood sandwich beams with lattice-web reinforcement in flatwise and sidewise directions," Construction and Building Materials, vol. 156, pp. 532-545, 2017.

[11] M. Osei-Antwi, J. de Castro, A. P. Vassilopoulos, and T. Keller, "Modeling of axial and shear stresses in multilayer sandwich beams with stiff core layers," Composite Structures, vol. 116, no. 1, pp. 453-460, 2014.

[12] N. A. Fleck and I. Sridhar, "End compression of sandwich columns," Composites Part A: Applied Science and Manufacturing, vol. 33, no. 3, pp. 353-359, 2002.

[13] V. P. Veedu and L. A. Carlsson, "Finite-element buckling analysis of sandwich columns containing a face/core debond," Composite Structures, vol. 69, no. 2, pp. 143-148, 2005.

[14] D. Zhu, H. Shi, H. Fang, W. Liu, Y. Qi, and Y. Bai, "Fiber reinforced composites sandwich panels with web reinforced wood core for building floor applications," Composites Part B: Engineering, vol. 150, pp. 196-211, 2018.

[15] T. Sharaf, W. Shawkat, and A. Fam, "Structural performance of sandwich wall panels with different foam core densities in one-way bending," Journal of Composite Materials, vol. 44, no. 19 , pp. 2249-2263, 2010.

[16] F. Ascione, M. Lamberti, A. G. Razaqpur et al., "Strength and stiffness of adhesively bonded GFRP beam-column moment resisting connections," Composite Structures, vol. 160, pp. 1248-1257, 2016.

[17] M. Correia, J. R. Correia, T. Keller, F. A. Kelle, and F. Branco, "Connection systems between composite sandwich floor panels and load-bearing walls for building rehabilitation," Engineering Structures, vol. 106, pp. 209-221, 2016.

[18] P. Wang, Z. Wang, and J. Pang, "Experimental investigation on behavior of stiffened top and seat angle beam-to-column connections in steel frame," Journal of Building Structures, vol. 38, no. 10, pp. 21-28, 2017, in Chinese.

[19] L. C. Bank, A. S. Mosallam, and H. E. Gonsior, "Beam-tocolumn connections for pultruded FRP structures," in Proceedings of the 1st Materials Engineering Congress, Materials Engineering Division, Denver, CO, USA, 1990.

[20] L. C. Bank, A. S. Mosallam, and G. T. McCoy, "Design and performance of connections for pultruded frame structures," Journal of Reinforced Plastics and Composites, vol. 13, no. 3, pp. 199-212, 1994.

[21] J. T. Mottram and Y. Zheng, "Further tests on beam-to-column connections for pultruded frames: web-cleated," Journal of Composites for Construction, vol. 3, no. 1, pp. 3-11, 1999.

[22] J. T. Mottram and Y. Zheng, "Further tests of beam-to-column connections for pultruded frames: flange-cleated," 
Journal of Composites for Construction, vol. 3, no. 3, pp. 108-116, 1999.

[23] F. Ascione, L. Feo, M. Lamberti et al., "Experimental and numerical evaluation of the axial stiffness of the adhesive connections in composite beams," Composite Structures, vol. 176, pp. 702-714, 2017.

[24] F. Ascione, A. G. M. Lamberti, and M. MalagicSpadea, "Pseudo-ductile failure of adhesively joined GFRP beamcolumn connections: an experimental and numerical investigation," Composite Structures, vol. 200, pp. 864-873, 2018.

[25] A.G. Razaqpur, F. Ascione, M. Lamberti, S. Spadea, and M. Malagic, "GFRP hollow column to built-up beam adhesive connection: mechanical behaviour under quasi-static, cyclic and fatigue loading," Composite Structures, vol. 224, 2019.

[26] British Standards Institute, Eurocode 3-design of Steel Structures Part 1.8: Design of Joints, British Standards Institute, London, UK, 2005.

[27] ASTM International, ASTM D3039/3039M-14. Standard Test Method for Tensile Properties of Polymer Matrix Composite Materials, ASTM International, West Conshohocken, PA, 2014.

[28] ASTM International, ASTM D3410/D3410M-16. Standard Test Method for Compressive Properties of Polymer Matrix Composite Materials with Unsupported Gage Section by Shear Loading, ASTM International, West Conshohocken, PA, 2016.

[29] ASTM International, ASTM C365/C365M-16. Standard Test Method for Flatwise Compressive Properties of Sandwich Cores, ASTM International, West Conshohocken, PA, 2016.

[30] ASTM International, ASTM E8/E8M-13a, Standard Test Method for Tension Testing of Metallic Materials, ASTM International, West Conshohocken, PA, 2013.

[31] S. Chen, Design Principle of Steel Structure, Science Press, Beijing, China, 2005, in Chinese, Third edition.

[32] Z. Guo and X. Shi, Theory and Analysis of Reinforced Concrete, pp. 163-337, Tsinghua University Press, Beijing, China, 2003, in Chinese.

[33] P. Feng, H. Qiang, and L. Ye, "Discussion and definition on yield points of materials, members and structures," Engineering Mechanics, vol. 3, pp. 41-51, 2017, in Chinese.

[34] P. Feng, S. Cheng, Y. Bai, and L. Ye, "Mechanical behavior of concrete-filled square steel tube with FRP-confined concrete core subjected to axial compression," Composite Structures, vol. 123, pp. 312-324, 2015.

[35] R. Park, "Ductility evaluation from laboratory and analytical testing," in Proceedings of the Ninth World Conference on Earthquake Engineering, pp. 605-616, Tokyo, Japan, 1998.

[36] GB 50017-2002, "Design method of local buckling and postbucking strengte for welded I-beams," Journal of Building Structures, vol. 23, no. 3, pp. 52-59, 2002, in Chinese. 